\title{
SEGMENTAÇÃO PSICOGRÁFICA DOS CONSUMIDORES DE ALIMENTOS ORGÂNICOS
}

\author{
PSYCHOGRAPHIC SEGMENTATION OF ORGANIC FOOD CONSUMERS
}

\author{
Wilson Ravelli Elizeu Maciel * \\ Mestre em Administração - Universidade Federal de Mato Grosso do Sul \\ Ubá, MG, Brasil \\ E-mail: wilson_ravelli@hotmail.com \\ Danilo Moraes de Oliveira \\ Mestre em Administração - Universidade Federal de Mato Grosso do Sul \\ Ubá, MG, Brasil \\ E-mail: danilo.m.o@hotmail.com \\ Dario de Oliveira Lima-Filho \\ Professor Doutor em Administração (Programa de Pós-graduação em Administração) - Universidade Federal \\ de Mato Grosso do Sul \\ Ubá, MG, Brasil \\ E-mail: dariolimafilho@gmail.com
}

\section{RESUMO}

O presente estudo teve como objetivo identificar o perfil psicográfico dos consumidores de alimentos orgânicos. Para tanto, foi realizado um estudo quantitativo-descritivo junto a 131 indivíduos. Utilizando-se das variáveis da escala VALS-2 (Valor e Estilo de Vida), foi desenvolvida uma análise fatorial, através da qual foram identificados os perfis psicográficos dos respondentes, em forma de sete fatores/dimensões, denominados: Orientado para a moda, Orientado para a auto-suficiência, Orientado para a inovação, Orientado para a liderança, Orientado para a auto-afirmação, Orientado para a descoberta/busca e Orientado para o tradicionalismo. Submetendo-se estes fatores à Análise de Agrupamento (Cluster), verificou-se que os segmentos mais relevantes foram: Orientado para a auto-afirmação, Orientado para a liderança e Orientado para a descoberta/busca. Desta forma, a partir da análise das variáveis que compõem estes segmentos, concluiu-se que este nicho se caracteriza por indivíduos em situação de liderança, que visam um diferencial, o aprimoramento e o conhecimento.

Palavras-chave: Alimentos orgânicos. Consumidores de alimentos orgânicos. Segmentação psicográfica. VALS-2. Estilo de vida.

\section{ABSTRACT}

The present study aimed to identify the psychographic profile of consumers of organic food. Thus, was conducted a quantitative-descriptive study with 131 individuals. Through the use of the variables from VALS-2 scale (Value and Life Style), being made a factor analysis, were identified the psychographic profiles of respondents, in the form of seven factors/dimensions, denominated: Oriented to fashion, Oriented to self-sufficiency, Oriented to innovation, Oriented to leadership, Oriented to self-assertion, Oriented to the discovery/search and Oriented to the traditionalism. Submitting these factors to Cluster Analysis (Cluster), it was found that the most relevant segments were: Oriented to self-assertion, Oriented to leadership and oriented towards the discovery/search. Thus, from the analysis of the variables that make up these segments, it was concluded that this niche is characterized by individuals in a position of leadership, that aimed at a differential, the improvement and the knowledge.

Keywords: Organic food. Organic food consumers. Psychographic segmentation. VALS-2. Lifestyle.

Data de aprovação: 4 de junho de 2016.

Data de submissão: 7 de novembro de 2015. 


\section{INTRODUÇÃO}

A difusão e crescimento da consciência ambiental e do interesse em alimentos mais seguros à saúde têm levado ao questionamento das práticas e processos do modelo de agricultura convencional (química). Além deste fato, potenciais riscos em função da utilização de pesticidas e de seus resíduos nos alimentos e meio ambiente são associados a desconhecidos efeitos à saúde no longo prazo (MEI-FANG, 2007).

Segundo o Ministério da Agricultura, Pecuária e Abastecimento (MAPA, 2011), para que um produto possa ser considerado orgânico, o mesmo deve ser produzido em um ambiente segundo os princípios agroecológicos, contemplando o uso responsável do solo, da água, do ar e dos demais recursos naturais utilizados no processo produtivo. Além disso, fica descartada a utilização de substancias como fertilizantes sintéticos solúveis, agrotóxicos e sementes transgênicas.

De acordo com Dettmann e Dimitri (2009), o segmento de produtos orgânicos é o que mais cresce no setor alimentício dos Estados Unidos, com taxas médias de crescimento entre 1998 e 2006 de 17\% ao ano. No Brasil o mercado de produtos orgânicos movimentou por volta de $\mathrm{R} \$ 350$ milhões em 2010, sendo que este montante representa um crescimento de $40 \%$ em relação ao obtido em 2009 , mostrando assim, que o Brasil possui um crescimento do mercado de orgânicos acima da expectativa mundial, sendo esta $20 \%$ (BRASIL, 2011).

Neste âmbito, segundo Rozin, Fischler e Shields-Argelès (2012), muitas pesquisas devem ser realizadas em torno da preferência dos consumidores por produtos naturais, especialmente fora dos Estados Unidos, tanto nos países desenvolvidos quanto nos menos desenvolvidos ou em desenvolvimento.

Em vista deste cenário, torna-se relevante identificar e explorar quais são os valores e estilos de vida adotados por este público, a fim de um melhor entendimento de quais princípios estes podem estar pautados quando do consumo de algum bem. Uma abordagem bastante relevante para tal é a análise psicográfica, a qual analisa, mediante respostas do consumidor, fatores no âmbito de seus valores e personalidade dividindoos em diferentes grupos. Segundo Blackwell, Miniard e Engel (2011), um dos modelos mais relevantes e adotados para tal finalidade é o VALS-2 (Values and Life Style), sendo este composto por 35 variáveis alocadas em oito dimensões/segmentos, sendo estas variáveis tomadas nesta pesquisa como a diretriz para a segmentação dos consumidores de alimentos orgânicos.

Em torno da problemática: Qual o estilo de vida dos consumidores de alimentos orgânicos?, a presente pesquisa pretende, através das variáveis do modelo VALS-2, identificar as dimensões de comportamento adotadas pelos consumidores de alimentos orgânicos de Campo Grande-MS, que se traduzem em seu estilo de vida. 


\section{FUNDAMENTAÇÃO TEÓRICA}

Segundo Kohlrausch, Campos e Selig (2004) devido a insustentabilidade dos padrões atuais de consumo, além das crescentes preocupações ambientais e com a saúde, intensificou-se a formulação de teorias, modelos e políticas que se apoiam em um modelo de consumo que promova um desenvolvimento sustentável.

Este contexto, que fica cada vez mais difundido em função da facilidade de acesso às informações faz com que se ocorra uma evolução gradativa das atitudes de consumo em torno da origem do alimento (HUGHNER et al, 2007). Sendo um dos resultados, a procura cada vez maior por alimentos orgânicos (ARCHANJO; BRITO; SAUERBECK, 2001).

Segundo Solomon (2002), a escolha do consumidor é um reflexo das diretrizes expressas por seus valores, gostos e preferências. Meireles et al (2004) reforça que ao consumirem, os indivíduos mostram sua identidade, características, personalidade, valores e estilos de vida. Quanto a este último, Engel, Blackwell e Miniard (1995) definem como um modelo que apresenta os padrões aos quais os indivíduos são pautados, no que se refere ao modo como gastam seu tempo e dinheiro, refletindo este, as atividades, interesses e opiniões dos mesmos.

De acordo com Kamakura e Wedel (1995), as características do estilo de vida fornecem importantes informações do indivíduo e seu life-like, fazendo dos modelos de retratação de estilos de vida uma opção muito utilizada pelos profissionais de marketing para o auxílio à tomada de decisão.

Desta forma, a segmentação psicográfica se mostra uma alternativa de relevante importância para uma melhor identificação de grupos homogêneos dentro de um segmento de consumidores, possibilitando as organizações atenderem mais especificamente as expectativas e estilo de consumo dos indivíduos. Segundo Blackwell, Miniard e Engel (2011), um dos modelos de segmentação psicográfica mais amplamente utilizados é o VALS-2 (Values and Life Style).

Segundo a Stanford Research Institute (SRI) (2006), detentora do modelo VALS de segmentação psicográfica, sua abordagem foi concebida originalmente pelo pesquisador Arnold Mitchell, o qual buscava explicações para as mudanças de valores e estilos e vida durante a década de 1970, nos Estados Unidos e, veio a ser inaugurado como produto da SRI em 1978 (SRI-BI, 2006).

Segundo Blackwell, Miniard e Engel (2011), o modelo enquadrava os indivíduos em nove tipos de estilos de vida distribuídos em três orientações:

a) Impulsionados pela necessidade: Sobreviventes e Sustentadores;

b) Direcionados externamente: Pertencentes, Emuladores e Realizadores;

c) Direcionados internamente: Eu-sou-eu, Experimentadores, Conscientes socialmente e integrados.

Contudo, o modelo foi redefinido na tentativa de maximizar a capacidade de prever o comportamento do consumidor e, em 1989, a partir desta necessidade, o modelo foi reformulado (VALS-2), baseando-se em traços de personalidade (auto-orientações) em detrimento dos valores sociais, sendo que este último muda com o passar do tempo (SRI-BI, 2006). Desta forma, o modelo VALS-2 ficou definido com oito segmentos de 
estilos de vida e três orientações (BLACKWELL; MINIARD; ENGEL, 2011; SRI-BI, 2006), podendo, esta estrutura, ser observada na Figura 1:

a) Orientados por princípios: Tomam decisões de compra baseando-se em seus princípios, opiniões e crenças, sem se deixar influenciar por outros indivíduos.

- Reflexivos: São indivíduos maduros, reflexivas, e bem educados. Tendem a pesquisar informações no processo de tomada de decisões. Valorizam fatores como ordem, conhecimento e responsabilidade. Como consumidores, prezam pela durabilidade, funcionalidade e valor dos produtos.

- Crentes: São Indivíduos fundamentalmente conservadores e fortemente tradicionalistas. São avessos a mudanças e possuem convicções concretas, baseadas em condutas tradicionalmente estabelecidas. Como consumidores, prezam por produtos familiares e marcas já estabelecidas.

b) Orientados pelo status: Tomam decisões de compras influenciadas por opiniões, crenças e pontos de vista dos outros indivíduos;

- Realizadores: São indivíduos orientados para a família e o sucesso na carreira. Tem vidas controladas e evitam situações que representam risco. Como consumidores, prezam por produtos que ajudam a demonstrar prestígio e sucesso aos outros;

- Esforçados: São indivíduos que buscam diversão, estar dentro da moda e a aprovação do mundo ao seu redor. Possuem poucos recursos e dão muito valor as opiniões de outros indivíduos. Como consumidores, prezam por produtos que imitem os que são comprados por pessoas com mais recursos.

c) Orientados pela ação: Tomam decisões de compras por produtos que afetam o seu ambiente, procuram variedade e são propícios a riscos.

- Experimentadores: Indivíduos mais jovens, impulsivos, gostam de experimentar o que não é convencional, do extravagante e do arriscado. Como consumidores, despendem boa parte da renda com itens relacionados à moda e entretenimento;

- Fazedores: Indivíduos práticos, que valorizam a autossuficiência e são conservadores. Como consumidores, prezam por produtos funcionais e básicos, baseando-se no valor e não no luxo.

Neste modelo, dois dos estilos de vida ficam fora das dimensões básicas, compondo suas dimensões à parte. Isto, levando em conta seu grau de recurso e inovação (SRI-BI, 2006):

- Inovadores: Indivíduos bem sucedidos e sofisticados. Estão em posição de liderança, são os mais receptivos a novas ideias, são interessados no crescimento, na inovação e em mudanças. Como consumidores, prezam por produtos de maior luxo e seletividade;

- Lutadores: São indivíduos mais pobres, com o nível de qualificação e educação menos avançados, suas preocupações são a saúde e a segurança. Como consumidores, agem cautelosamente, são leais às marcas e buscam descontos. 
Figura 1 - Estrutura do modelo VALS-2

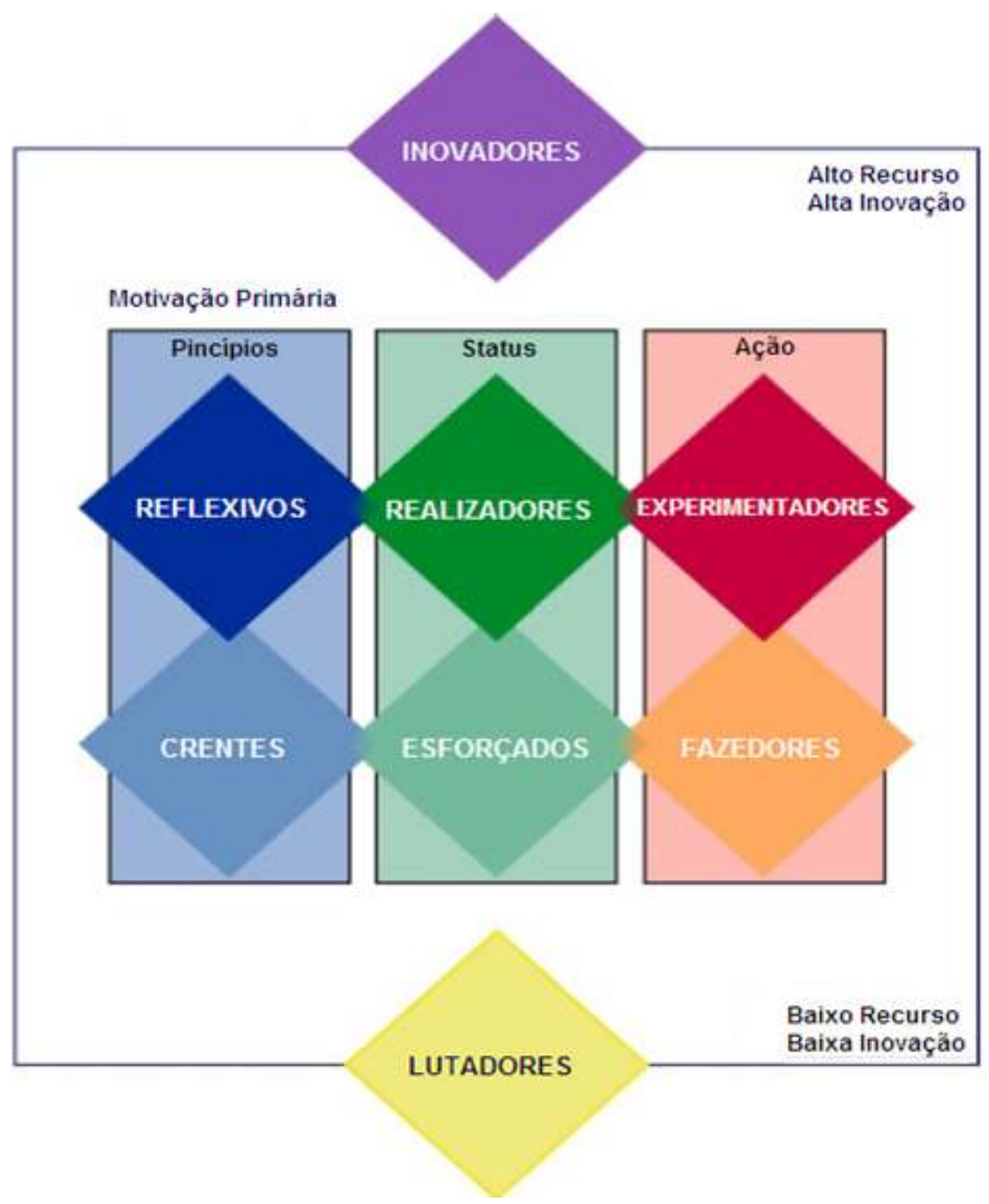

Fonte: Elaborada pelos autores, adaptado de SRI-BI (2006)

\section{PROCEDIMENTOS METODOLÓGICOS}

A fim de identificar as dimensões de comportamento adotadas pelos consumidores de alimentos orgânicos de Campo Grande-MS, que se traduzem em seu estilo de vida, foi conduzida uma pesquisa de abordagem quantitativa e, quanto aos fins, teve caráter descritivo (VERGARA, 2005). O universo analisado foi composto por consumidores de alimentos orgânicos de Campo Grande-MS.

A técnica de amostragem adotada foi de natureza não-probabilística (por conveniência). Para a coleta de dados foi elaborado um questionário estruturado (MALHOTRA, 2001), aplicado a 131 indivíduos do universo pesquisado, sendo que destes questionários quatro foram descartados por estarem preenchidos de forma inadequada. Assim, a amostra trabalhada foi de 127 indivíduos.

O questionário em questão foi composto pelas 35 variáveis do modelo VALS-2 (SRI-BI, 2006), três questões para identificação do perfil socioeconômico da amostra (sexo, faixa-etária e escolaridade), além da 
pergunta-filtro sobre a regularidade no consumo de alimentos orgânicos, sendo determinado como regular, o consumo destes alimentos ao menos três vezes durante a semana.

Para a mensuração das variáveis do modelo psicográfico VALS-2, de acordo com os valores e atitudes da amostra pesquisada, foi utilizada Escala Likert de cinco pontos (1-Discordo Totalmente, 2Discordo Parcialmente, 3-Nem Concordo/Nem Discordo, 4-Concordo Parcialmente, 5-Concordo Totalmente), apresentada conforme Figura 2.

Figura 2 - Variáveis do modelo VALS-2 dotadas de Escala Likert de cinco pontos

\begin{tabular}{|c|c|c|c|c|c|c|}
\hline \multicolumn{2}{|r|}{ AFIRMATIVAS } & \multirow{2}{*}{ 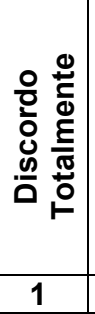 } & \multirow{2}{*}{ 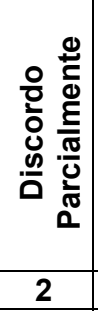 } & \multirow{2}{*}{ 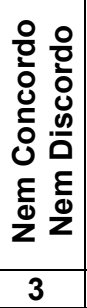 } & \multirow{2}{*}{ 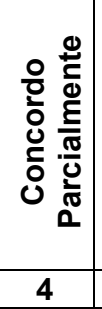 } & \multirow{2}{*}{ 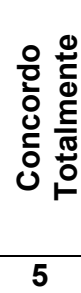 } \\
\hline & & & & & & \\
\hline 1 & Sempre estou interessado em teorias & & & & & \\
\hline 2 & Gosto de pessoas e coisas extravagantes & & & & & \\
\hline 3 & Gosto de muita variedade na minha vida & & & & & \\
\hline 4 & Gosto de fazer ou criar coisas que eu possa usar & & & & & \\
\hline 5 & Sigo as últimas tendências e modas & & & & & \\
\hline 6 & Conforme diz a Bíblia, o mundo realmente foi criado em seis dias & & & & & \\
\hline 7 & Gosto de estar no comando de um grupo & & & & & \\
\hline 8 & Gosto de aprender sobre arte, cultura e história & & & & & \\
\hline 9 & Anseio por coisas excitantes & & & & & \\
\hline 10 & Interesso-me realmente por poucas coisas & & & & & \\
\hline 11 & Prefiro fazer ou construir algo ao invés de comprar & & & & & \\
\hline 12 & Visto-me mais na moda do que a maioria das pessoas & & & & & \\
\hline 13 & O governo deveria incentivar a prática de rezar nas escolas & & & & & \\
\hline 14 & Tenho mais habilidade do que a maioria das pessoas & & & & & \\
\hline 15 & Considero-me um(a) intelectual & & & & & \\
\hline 16 & Devo admitir que gosto de me exibir & & & & & \\
\hline 17 & Gosto de experimentar coisas novas & & & & & \\
\hline 18 & $\begin{array}{l}\text { Sou muito interessado em saber como coisas mecânicas (como } \\
\text { motores, por exemplo) funcionam }\end{array}$ & & & & & \\
\hline 19 & Gosto de me vestir na última moda & & & & & \\
\hline 20 & Há muito sexo na TV hoje em dia & & & & & \\
\hline 21 & Gosto de liderar & & & & & \\
\hline 22 & Gostaria de passar um ano ou mais em outro país & & & & & \\
\hline 23 & Gosto de muita agitação na minha vida & & & & & \\
\hline 24 & Devo admitir que meus interesses são um pouco restritos e limitados & & & & & \\
\hline 25 & Gosto de fazer coisas de madeira, metal ou outros materiais & & & & & \\
\hline 26 & Quero ser considerado (a) uma pessoa que anda na moda & & & & & \\
\hline 27 & $\begin{array}{l}\text { A vida de uma mulher só está completa se ela pode propiciar um lar feliz } \\
\text { em sua família }\end{array}$ & & & & & \\
\hline 28 & Gosto do desafio de fazer algo que eu nunca tinha feito antes & & & & & \\
\hline 29 & Gosto de aprender sobre coisas, mesmo que elas nunca me sejam úteis & & & & & \\
\hline 30 & Eu gosto de fazer coisas com minhs proprias mãos & & & & & \\
\hline 31 & Estou sempre buscando emoções & & & & & \\
\hline 32 & Gosto de fazer coisas novas e interessantes & & & & & \\
\hline 33 & Gosto de olhar lojas de carros e máquinas & & & & & \\
\hline 34 & Gostaria de aprender mais sobre como o Universo funciona & & & & & \\
\hline 35 & Gosto que minha vida seja sempre a mesma & & & & & \\
\hline
\end{tabular}

Fonte: Elaborado pelos autores

Para que fosse verificada a compreensão e didática do questionário, foi realizado um pré-teste junto a quinze estudantes do $7^{\circ}$ semestre do curso de administração da Universidade Federal de Mato Grosso do Sul (UFMS), em Campo Grande-MS, no dia 05/06/2012. 
A aplicação dos questionários à população alvo se deu nas Feiras de Produtos Orgânicos de Campo Grande-MS, as quais acontecem às quartas-feiras e aos sábados na região central da cidade. Foram aplicados 53 questionários na feira realizada no sábado, no dia 09/06/2012 e 78 na feira realizada na quartafeira, no dia 13/06/2012.

Para a análise dos dados utilizou-se métodos de estatística multivariada, mais especificamente, da Análise Fatorial (MINGOTI, 2005), com o auxílio do software estatístico SPSS 15.0 (SPSS, 2006), para a condensação das variáveis presentes no modelo VALS-2 em fatores e, da Análise de Agrupamento (Cluster) (MINGOTI, 2005), com o auxílio do software estatístico MINITAB 12.1 (LEE, 2000), para determinar por quais grupos se dá a composição do estilo de vida dos consumidores de alimentos orgânicos de Campo GrandeMS.

\section{ANÁLISE E DISCUSSÃO DOS RESULTADOS}

Para a caracterização da amostra, faz-se necessário, primeiramente, a análise do seu perfil socioeconômico, devido a importância de se conhecer quem são os indivíduos respondentes (Tabela 1).

Tabela 1 - Dados socioeconômicos da amostra

\begin{tabular}{|c|c|c|c|}
\hline \multicolumn{2}{|c|}{ Sexo } & \multicolumn{2}{|c|}{ Faixa etária } \\
\hline Masculino & $45,7 \%$ & De 20 a 29 anos & $7,1 \%$ \\
\hline Feminino & $54,3 \%$ & De 30 a 39 anos & $12,6 \%$ \\
\hline \multicolumn{2}{|c|}{ Escolaridade } & De 40 a 49 anos & $31,5 \%$ \\
\hline Ensino Fun & $11,8 \%$ & De 50 a 60 anos & $30,7 \%$ \\
\hline Ensino Méc & $34,6 \%$ & Mais de 60 anos & $18,1 \%$ \\
\hline Ensino Sup & $45,7 \%$ & & \\
\hline
\end{tabular}

Fonte: Dados da pesquisa

Com relação ao sexo, conforme fica evidenciado na Tabela 1, a maioria da amostra é composta por indivíduos do sexo feminino ( $54,3 \%$ contra $45,7 \%$ de indivíduos do sexo masculino). Sendo este um resultado um pouco desequilibrado, contudo, se comparado a outras pesquisas como as de Rucinski e Brandenburg (2002) e Kohlrausch et al (2004), vemos que a tendência da predominância do sexo feminino é ainda maior nas cidades onde estes autores pesquisaram, sendo, respectivamente, em Curitiba-PR e Florianópolis-SC, onde os consumidores do sexo feminino correspondiam, respectivamente, a $66 \%$ e $76 \%$

Com relação a faixa-etária, conforme fica evidenciado na Tabela 1, o grupo em que se concentram mais indivíduos é de 40 a 49 anos (31,5\%), seguida das pessoas entre 50 a 60 anos $(30,7 \%)$, o que nos mostra que os alimentos orgânicos são consumidos por pessoas de maior idade, onde $62,5 \%$ da amostra se concentra nestas duas faixas-etárias. Semelhante a este resultado, na pesquisa de Kohlrausch et al (2004), vemos a faixa etária de 36 a 50 anos como a predominante $(42,5 \%)$. Seguindo esta tendência, temos também a pesquisa de Nie e Zepeda (2010), onde o grupo em que mais se concentravam consumidores de alimentos orgânicos apresentava-se com faixa etária predominantemente de 45 a 54 anos. Porém, na pesquisa de Rucinski e Brandenburg (2002) observou-se a faixa etária de 31 a 40 anos como predominante, sendo o segundo grupo (28\%) composto por indivíduos de faixa etária similar (40 a 49 anos) as encontradas na pesquisa de Kohlrausch et al (2004) e na presente pesquisa. 
Com relação a escolaridade, conforme fica evidenciado na Tabela 1, a maior parte da amostra $(53,6 \%)$ é composta por indivíduos que possuem até o ensino superior. Estes resultados são semelhantes aos encontrados nas pesquisas de Rucinski e Brandenburg (2002) e Kohlrausch et al (2004), onde o grupo mais predominante entre os indivíduos que consumiam alimentos orgânicos era o dos que possuíam o ensino superior, correspondendo, respectivamente, a $58 \%$ e $55 \%$ da amostra, relação entre consumo de alimentos orgânicos e escolaridade também encontrado em pesquisa de Nie e Zepeda (2010).

Após a análise do perfil socioeconômico da amostra, foi feita a condensação das variáveis do modelo VALS-2 em dimensões principais, através da Análise Fatorial, tendo como principal ferramenta de avaliação da adequabilidade dos dados à análise a medida KMO (Kaiser-Meyer-Olkin) e o valor da correlação antiimagem das variáveis (MINGOTI, 2005). O processo da análise segue abaixo:

Processamento 1: As 35 variáveis do modelo VALS-2 foram utilizadas, obtendo-se 11 fatores, com um KMO de 0,656, o que demonstrou uma correlação linear entre os dados regular. Porém, as variáveis 1, 6, 8,18 e 27 obtiveram valor de correlação anti-imagem abaixo de 0,5 , o qual é tido como satisfatório por Hair et al. (2005).

Processamento 2: As variáveis 1, 6, 8, 18 e 27 e a análise foi processada. Desta forma, foram obtidos 10 fatores, com um valor de KMO de 0,705. No entanto, na matriz anti-imagem, a variável 13 obteve resultado abaixo de 0,5. Optando-se por excluí-la.

Processamento 3: Foram obtidos, novamente, 10 fatores, com um KMO de 0,710. No entanto, através do grau de comunalidade, foi observado que cinco variáveis obtiveram valor abaixo de 0,6, contudo, optouse por retirar apenas as variáveis 9 e 17, o que se justifica pelo fato de que as demais variáveis já faziam parte de fatores relevantes. Foi excluída também, a variável 33 , visto que que um fator era composto unicamente por ela.

Processamento 4: Foram obtidos nove fatores, com um KMO de 0,713. No entanto, optou-se por excluir a variável 23, buscando obter-se um melhor constructo dos fatores, por esta estar presente em dois.

Processamento 5: Foram obtidos 8 fatores, com um KMO de 0,703. No entanto, optou-se por excluir as variáveis 10,29 e 35 , buscando novamente, um melhor constructo dos fatores, por estas estarem presentes em dois fatores.

Processamento 6: Foram obtidos 7 fatores, com um KMO de 709. Buscando novamente um melhor constructo, a variável 2, por estar presente em dois fatores, foi excluída.

Processamento 7: Foram obtidos 7 fatores, com um KMO de 0,705. Tendo esta como o resultado definitivo da análise fatorial, conforme ilustrado nas tabelas 2 e 3 . Levando ainda em conta ainda que os valores de saturação das variáveis foram todos maiores do que 0,5 , sendo que para o valor da saturação poder ser considerado aceitável, este deve ser superior a 0,3 (ALVES, 2006).

Após a obtenção dos fatores, através da análise final, pôde-se definir e nomear as dimensões obtidas. Isto, através da análise do conjunto das variáveis que compões os fatores. Assim sendo, o Quadro 1 apresenta os sete fatores obtidos, as variáveis compreendidas nestes, além das nomeações das dimensões comportamentais dos fatores:

a) Fator 1-Moda/Status (variáveis: 26, 19, 05, 12 e 16): Diretrizes que remetem a um estilo de vida que valoriza a imagem do indivíduo perante as outras pessoas, se enquadram neste grupo as pessoas que 
buscam sempre apresentar boa aparência e ser um indivíduo "atualizado". Para estes a aparência diz muito sobre um indivíduo.

b) Fator 2 - Autossuficiente/Prático (variáveis: 11, 30, 04, 25): Diretrizes que remetem a um estilo de vida arrojado, com uma orientação à praticidade e funcionalidade.

c) Fator 3 - Inovador (variáveis: 31, 38, 03, 32): Diretrizes que remetem a um estilo de vida dotado de atitudes inovadoras. São indivíduos que primam experiências novas e estimulantes. Desta forma, este é um estilo de vida menos avesso a riscos em relação aos demais.

d) Fator 4 - Líder (variáveis: 21 e 7): Diretrizes que remetem a um estilo de vida voltado a autoridade e a liderar pessoas. São indivíduos que primam estar no comando, fornecendo as coordenadas para os demais.

e) Fator 5 - Autoafirmação (variáveis: 14 e 15) Diretrizes que remetem a um estilo de vida autoconfiante. São indivíduos que se consideram munidos de um maior grau de conhecimento, sendo isto, um diferencial perante os outros indivíduos, na busca da diferenciação e ser referência.

f) Fator 6 - Aprimoramento (variáveis: 34 e 22): Diretrizes que remetem a um estilo de vida com ênfase na busca frequente pelo conhecimento/aprimoramento. São indivíduos interessados.

g) Fator 7 - Tradicionalista (variáveis: 34 e 20): Diretrizes que remetem a um estilo de vida pautado em valores mais tradicionais/conservadores e restritos, sendo estes, indivíduos mais sistemáticos e avessos a riscos.

Tabela 2 - Fatores obtidos e a saturação de suas variáveis Matriz de Componentes Rotacionada

\begin{tabular}{|c|c|c|c|c|c|c|c|}
\hline \multirow{2}{*}{ Variáveis } & \multicolumn{7}{|c|}{ Fatores } \\
\hline & 1 & 2 & 3 & 4 & 5 & 6 & 7 \\
\hline 26 & 0,866 & & & & & & \\
\hline 19 & 0,795 & & & & & & \\
\hline 5 & 0,778 & & & & & & \\
\hline 12 & 0,774 & & & & & & \\
\hline 16 & 0,553 & & & & & & \\
\hline 11 & & 0,816 & & & & & \\
\hline 30 & & 0,734 & & & & & \\
\hline 4 & & 0,711 & & & & & \\
\hline 25 & & 0,547 & & & & & \\
\hline 31 & & & 0,756 & & & & \\
\hline 28 & & & 0,729 & & & & \\
\hline 3 & & & 0,727 & & & & \\
\hline 32 & & & 0,553 & & & & \\
\hline 21 & & & & 0,876 & & & \\
\hline 7 & & & & 0,832 & & & \\
\hline 14 & & & & & 0,834 & & \\
\hline 15 & & & & & 0,674 & & \\
\hline 34 & & & & & & 0,799 & \\
\hline 22 & & & & & & 0,744 & \\
\hline 24 & & & & & & & 0,780 \\
\hline 20 & & & & & & & 0,583 \\
\hline
\end{tabular}

Método de extração: Componentes principais

Fonte: dados da pesquisa 
Tabela 3 - KMO da análise final

\begin{tabular}{lrr}
\hline \multicolumn{3}{c}{ KMO and Bartlett's test } \\
\hline Kaiser-Meyer-Olkin Measure of Sampling Adequacy & 0,705 \\
\hline & Chi quadrado aproximado & 846,987 \\
Bartlett's test of Sphericity & Graus de liberdade & 210 \\
& Significância & 0,000 \\
\hline
\end{tabular}

Fonte: dados da pesquisa

Quadro 1 - Denominação dos fatores e suas variáveis

\begin{tabular}{|c|c|c|}
\hline Fator & Variáveis & $\begin{array}{c}\text { Dimensão/Orientação de } \\
\text { comportamento }\end{array}$ \\
\hline \multirow{5}{*}{1} & 26 - Quero ser considerado (a) uma pessoa que anda na moda & \multirow{5}{*}{ Moda/Status } \\
\hline & 19 - Gosto de me vestir na última moda & \\
\hline & 05 - Sigo as últimas tendências e modas & \\
\hline & 12 - Visto-me mais na moda do que a maioria das pessoas & \\
\hline & 16 - Devo admitir que gosto de me exibir & \\
\hline \multirow{4}{*}{2} & 11 - Prefiro fazer ou construir algo ao invés de comprar & \multirow{4}{*}{ Autossuficiente/Prático } \\
\hline & 30 - Gosto de fazer coisas com minhas próprias mãos & \\
\hline & 04 - Gosto de fazer ou criar coisas que eu possa usar & \\
\hline & 25 - Gosto de fazer coisas de madeira, metal ou outros materiais & \\
\hline \multirow{4}{*}{3} & 31 - Estou sempre buscando emoções & \multirow{4}{*}{ Inovador } \\
\hline & 28 - Gosto do desafio de fazer algo que eu nunca tinha feito antes & \\
\hline & 03 - Gosto de muita variedade na minha vida & \\
\hline & 32 - Gosto de fazer coisas novas e interessantes & \\
\hline \multirow{2}{*}{4} & 21 - Gosto de liderar & \multirow{2}{*}{ Líder } \\
\hline & 07 - Gosto de estar no comando de um grupo & \\
\hline \multirow{2}{*}{5} & 14 - Tenho mais habilidade do que a maioria das pessoas & \multirow{2}{*}{ Autoafirmação } \\
\hline & 15 - Considero-me um (a) intelectual & \\
\hline \multirow{2}{*}{6} & 34 - Gostaria de aprender mais sobre como o Universo funciona & \multirow{2}{*}{ Aprimoramento } \\
\hline & 22 - Gostaria de passar um ano ou mais em outro país & \\
\hline \multirow{2}{*}{7} & 24 - Devo admitir que meus interesses são restritos e limitados & \multirow{2}{*}{ Tradicionalista } \\
\hline & 20 - Há muito sexo na TV hoje em dia & \\
\hline
\end{tabular}

Fonte: Elaborado pelos autores

Outro estudo que se utilizou das variáveis do modelo VALS-2, submetendo-as a análise Fatorial foi realizado por Carvalho et al (2006), onde o qual buscava identificar a composição do estilo de vida de estudantes de pós-graduação de Londrina-PR e Uberlândia-MG. Foram obtidos oito faores, nomeados por ele: Inovador, Orientado para a moda, Prático, um grupo não identificável, Líder de grupo ou pessoas, Orientados para moral e religião, Teórico e Arrojado, sendo possível encontrar semelhanças entre este estudo e a presente pesquisa, como ocorre com o primeiro fator, onde se assemelham com o terceiro fator desta pesquisa no título dado e por apresentarem em comum, as variáveis 28,31 e 32 . Assim como o segundo fator da pesquisa de Carvalho et al (2006) (Orientado para a moda) se assemelha com o primeiro fator da presente pesquisa (Moda/Status), além de terem em comum as variáveis 5, 12, 19 e 26. Outra notória semelhança 
entre os estudos se dá no fator chamado por Carvalho et al (2006) de "Prático" e neste presente estudo, de "Autossuficiente/Prático", sendo as variáveis 25, 11 e 19 comum aos dois.

Após a Análise fatorial, que resultou nos fatores, aplicou-se a Análise de Agrupamento (Cluster) para apontar os fatores mais significativos no que diz respeito ao estilo de vida do consumidor de alimentos orgânicos de Campo Grande-MS, sendo esta, feita utilizando-se dos sete fatores obtidos com a utilização da Análise Fatorial, onde a partir deste ponto, os Clusters foram divididos em conformidade com as notas atribuídas aos fatores, ficando os estilos de vida assim organizados (Tabela 4):

Tabela 4 - Composição do estilo de vida

\begin{tabular}{lr}
\hline Fatores & Percentual \\
\hline Fator 1 - Moda/Status & $11,02 \%$ \\
\hline Fator 2 - Autossuficiente/Prático & $14,17 \%$ \\
\hline Fator 3 - Inovador & $11,02 \%$ \\
\hline Fator 4 - Líder & $17,32 \%$ \\
\hline Fator 5 - Autoafirmação & $22,05 \%$ \\
\hline Fator 6 - Aprimoramento & $16,54 \%$ \\
\hline Fator 7 - Tradicionalista & $7,87 \%$ \\
\hline Fonte: dados da pesquisa
\end{tabular}

Após a Análise de Agrupamento (Cluster), podemos verificar a composição do estilo de vida dos indivíduos analisados, ficando assim evidenciado que a dimensão/orientação de comportamento que mais está presente no estilo de vida dos consumidores de produtos orgânicos de Campo Grande-MS é a "Autoafirmação", seguida da dimensão "Líder", sendo que como foi exposto anteriormente, no caso da primeira, são indivíduos que possuem maior grau de conhecimento, fazendo disto, um diferencial perante os outros indivíduos, na busca de destaque e, no caso da segunda, são indivíduos que primam estar no comando, fornecendo as coordenadas para os demais.

$\mathrm{Na}$ terceira dimensão mais significativa da amostra está "Aprimoramento", seguido da dimensão Autossuficiente/Prático e, como quinta dimensão, ficam empatadas "Moda/Status" e "Inovador" e, por último e com considerável disparidade, está a dimensão "Tradicionalista".

Em pesquisa de Biemas (2011) na Polônia, onde foram identificados, através da análise Cluster, cinco segmentos: Tradicionalistas, Descuidados, Conscientes, Pragmáticos e Sem identificação. O grupo onde mais se consumia alimentos orgãnicos eram o dos "Consientes", que no que diz respeito ao estilo de vida, são pessoas geralmente abertas a novidades, o que podemos relacionar ao resultado da presente pesquisa, à medida que nesta o grupo mai relevante é caracterizado pela busca a um diferencial e o grupo menos relevante é o caracterizado pelos "Tradicionalistas", que são avessos a riscos e novas experiências. 


\section{CONSIDERAÇÕES FINAIS}

Este estudo teve como objetivo identificar as dimensões de comportamento adotadas pelos consumidores de alimentos orgânicos de Campo Grande-MS. Assim, foi conduzida uma pesquisa junto a uma amostra de 131 indivíduos de abordagem quantitativa e, quanto aos fins, de caráter descritivo.

Para a análise dos dados obtidos, utilizou-se de estatística descritiva, sendo utilizadas as técnicas de Análise Fatorial e Análise Cluster, para a identificação dos fatores predominantes na composição do estilo de vida dos consumidores de alimentos orgânicos de Campo Grande-MS.

Os resultados indicam que a maioria destes consumidores é do sexo feminino, com faixa etária elevada (40 a 60 anos) e com alto nível de escolaridade. Através da análise fatorial, revelaram-se sete fatores/dimensões de estilo de vida: Moda/Status, Autossuficiente/Prático, Inovador, Líder, Autoafirmação, Aprimoramento e Tradicionalista. Posteriormente, através da Análise de Agrupamento (Cluster), apontou-se os fatores/estilos mais relevantes no comportamento do nicho em questão, sendo estabelecida a seguinte distribuição da relevância: Autoafirmação (22,05\%), Líder (17,32\%), Aprimoramento (16,54\%), Autossuficiência (14,17\%), Moda/Status (11,02\%), Inovador (11,02\%) e, por fim, Tradicionalista $(7,87 \%)$.

Desta forma, o estudo identificou as dimensões predominantes de estilo de vida dos consumidores de alimentos orgânicos, as quais sejam: "Autoafirmação", "Líder" e "Aprimoramento". Sendo, de forma geral, grupos nos quais os indivíduos se caracterizam por estar em situação de liderança, buscam um diferencial e mais conhecimento, sendo estes resultados coerentes com estudos neste âmbito em outros países.

Considerando-se o fato de que a segmentação de mercado é, na maioria das vezes realizada pautando-se apenas nos dados socioeconômicos, a utilização da psicografia traz um avanço referente ao estudo do comportamento do consumidor. Neste âmbito, a pesquisa buscou ser de utilidade à área acadêmica, por trazer um compilado existente na literatura a respeito da análise psicográfica, suas aplicações e suas contribuições, para a área comercial, no âmbito de instigar pesquisas referentes ao estilo de vida dos consumidores. No âmbito das políticas públicas, através do exposto na pesquisa, no tocante ao consumo de alimentos orgânicos e as variáveis socioeconômicas, estão ricos dados que podem servir de ajuda à justificativa para o desenvolvimento de políticas voltadas a estimular o consumo de alimentos pelos indivíduos de menor escolaridade e renda.

A pesquisa em questão abrangeu apenas o município de Campo Grande-MS e obteve um tamanho de amostra reduzido $(n=131)$. Assim, sugere-se para estudos posteriores a replicação deste estudo em amostras mais significativas e em diferentes localidades do Brasil, isto, com o intuito de verificar e comparar a composição do estilo de vida dos consumidores de alimentos orgânicos em âmbito nacional. 


\section{REFERÊNCIAS}

ALVES, A. L. et al. Padrões alimentares de mulheres adultas residentes em área urbana no Sul do Brasil. Revista de Saúde Pública, v. 40, n. 5, p. 865-873, 2006.

ARCHANJO, L.R.; BRITO, K.F.; SAUERBECK, S. Alimentos orgânicos em Curitiba: consumo e significado. Caderno de Debates, Curitiba, v. 8, p. 1-6, 2001.

BIEMANS, S. Z. Polish consumer food choices and beliefs about organic food. British Food Journal, Warsaw, Poland, v. 113, n. 1, p. 122-137, 2011

BLACKWELL, R. D.; MINIARD, P. W.; ENGEL, J. F. Comportamento do consumidor. Tradução: Eduardo Teixeira Ayrosa. 9ed. São Paulo: Thomson, 2011.

BRASIL. Ministério da Agricultura, Pecuária e Abastecimento (MAPA). Comissão de produção orgânica, 2011. Disponível em: <http://www.prefiraorganicos.com.br/agrorganica/cporgs.aspx>. Acesso em: 19 dez. 2012.

BRASIL. Ministério da Agricultura, Pecuária e Abastecimento (MAPA). Consumo de orgânicos leva mercado interno a crescer 40\% em 2010, 2011. Disponível em:

<http://www.brasil.gov.br/noticias/arquivos/2011/02/03/consumo-de-organicos-leva-mercado-interno-a-crescer-40-em2010>. Acesso em: 19 dez. 2012

CARVALHO, D. T. ; SHINYASHIKI, G. T. ; BACCARO, T. A. ; BUIATTI, C. L. . Aplicação do Sistema Psicográfico VALS2 em Alunos de Pós-graduação de Londrina-PR e Uberlândia-MG. In: EMA- Encontro de Marketing da ANPAD, 2006, Rio de Janeiro. Anais do Encontro de Marketing da ANPAD 2006, 2006.

DETTMANN, R. L.; DIMITRI, C. Who's Buying Organic Vegetables? Demographic Characteristics of U.S. Consumers, Journal of Food Products Marketing, London, UK. v. 16, n. 1, p. 79-91, 2009.

ENGEL, J. F.; BLACKWELL, R.D.; MINIARD, Paul W. Comportamento do Consumidor. Rio de Janeiro: LTC - Livros Técnicos e Científicos S.A., 1995

HAIR, J. F.; ANDERSON, R. E.; TATHAM, R. L.; BLACK, Willian. Análise Multivariada de Dados. 5.ed. Porto Alegre: Bookman, 2005.

HUGHNER, R. S. et al. Who are organic food consumers? A compilation and review of why people purchase organic food. Journal of Consumer Behaviour. v. 6, n. 1, p. 94-110, 2007.

KAMAKURA, W. A.; WEDEL, M. Life-Style Segmentation With Tailored Interviewing. Journal of Marketing Research EUA, v. 32, p. 308-317, 1995.

KOHLRAUSCH, A. K.; CAMPOS, L. M.; SELIG, P. M. O comportamento do consumidor de produtos orgânicos em Florianópolis: Uma abordagem estratégica. Revista Alcance, Florianópolis, v. 11, n. 1, p. 157-177, 2004.

LEE, J. C. Business and financial statistics using Minitab 12. Hackensack, NJ: World

Scientific Publishing, 2000.

MALHOTRA, N. K. Pesquisa de marketing: uma orientação aplicada. Tradução: Nivaldo Montigelli e Alfredo Alves. 3. ed. Porto Alegre: Bookman, 2001.

MEI-FANG, C. Consumer attitudes and purchase intentions in relation to organic foods in Taiwan: moderating effects of food-related personality traits. Food Quality and Preference, v. 18, n. 7, p. 1008-1021, Out. 2007

MEIRELES, R. et al. Comportamento do consumidor e pesquisa de mercado. 1 ed., Rio de Janeiro: FGV, 2004.

NIE, C.; ZEPEDA, L. Lifestyle segmentation of US food shoppers to examine organic and local food Consumption. Appetite Journal, Madison, EUA, v. 57, p 28-37, 2011.

MINGOTI, S. A. Análise de dados através de métodos de estatística multivariada. Belo Horizonte: Editora UFMG, 2005.

ROZIN, P.; FISCHLER, C.; SHIELDS-ARGELĖS, C. European and American perspectives on the meaning of natural. Appetite, v. 59, p. 448-455, 2012.

RUCINSKI, J. M.; BRANDEBURG, A. Consumidores de alimentos orgânicos em Curitiba. In: I Encontro Nacional de Pós-graduação e Pesquisa em Meio Ambiente e Sociedade, 2002, Indaiatuba.

SOLOMON, M. R. O comportamento do consumidor: comprando, possuindo e sendo.5. ed., Porto Alegre: Brookman, 2002.

SPSS - Statistical Package for the Social Sciences. Manual del usuario de SPSS Base 15.0. 2006. Disponível em: <http://unorte.edu.uy/ccss/mtubio/SPSS\%20Base\%20User\%27s\%20Guide\%2015.0.pdf>. Acesso: 07 fev. 2013.

SRI-BI - SRI Business Consulting Intelligence. 2006. Disponível em: <http://www.nr.edu/itp160/assigns/05-valspersonality-types.pdf>. Acesso: 20 dez. 2012.

VERGARA, S. C. Projetos e Relatórios de Pesquisa em Administração. São Paulo: Atlas, 2005. 